\title{
Editorial
}

\section{Nos falta educación}

\author{
We lack education
}

Se nota cuando una persona tiene educación, y también se advierte cuando no la tiene. Esto es así porque en principio la educación no es algo etéreo, no es algo adscrito a la dimensión del intelecto o de la mente, ni tampoco es un valor abstracto como la esperanza ni un bien intangible como el conocimiento -como se podría pensar; sino un atributo evidente de una persona y este atributo se manifiesta en una variedad de formas. ¿Pero cómo palpamos esa cualidad o la falta de ese atributo perceptible dado por la educación? Para eso debemos tener alguna claridad conceptual de lo que entendemos por educación.

Educación es un término de uso muy común que además es utilizado en un sentido abierto para significar casi cualquier cosa, por esta razón su significado ha sido confundido y, demasiado a menudo, mal interpretado. Para el caso, generalmente, se confunde educación con escolarización y con instrucción. También se confunde con inculcación y adoctrinamiento e incluso con adiestramiento. En cambio, otros vinculan su significación indefectiblemente con procesos de enseñanza-aprendizaje.

Ante esta confusión es necesario aclarar que el término "escolarización" más bien hace referencia tanto al número de años que un individuo permanece en el sistema educativo escolar como a un tipo específico de educación: la que se imparte en la escuela que, dicho sea de paso, no es la única fuente que dispensa educación. La escuela, es decir, la escolarización, sirve para que los niños adquieran los conocimientos y experiencias en un entorno socializante más amplio que el hogar no puede proporcionar. La educación escolarizada cumple con una función social latente y privilegia el desarrollo cognitivo e intelectual, así como las competencias laborales más que la educación propiamente dicha. Una persona escolarizada, entonces, solo implica que ha 
recibido conocimientos, disciplinas, valores, actitudes y habilidades -necesarios en el mejor entender de la escuela- para que la persona asuma una vida adulta como sujeto laboral y social dentro de un contexto socio-económico específico y temporalmente situado.

Por otro lado, la instrucción hace referencia a la adquisición y acumulación de conocimientos -datos e información. De aquí que una persona instruida -con instrucción-no es necesariamente una persona educada ya que la acumulación de conocimientos no equivale a acumulación de educación. Eso que se da en llamar "educación escolar" tiene a menudo, un enfoque eminentemente instructivo. Demás está decirlo entonces, por obvio, que educación es mucho más que instrucción. De ahí que el problema de la educación no se resuelve con la escolarización ni con la instrucción.

Educación tampoco ha de confundirse con inculcación, ya que inculcación hace referencia al modo particular, a la mediación por la cual se implanta -para "bien" o para "mal"- una forma de pensar y sentir en una persona. Tampoco ha de entenderse como adiestramiento, ya que este tiene una connotación demasiado acotada al desarrollo de destrezas, ni con adoctrinamiento que se refiere a cuerpos de ideas o conocimientos específicos como en una ciencia que inducen a formas específicas de pensar y entender el mundo-. Todos estos términos de alguna forma se vinculan con la educación o en alguna medida son parte de ella, pero ninguno la explica totalmente per se.

¿Entonces, qué se ha de entender por educación? Más allá de las definiciones de diccionario, enciclopedia, manual de pedagogía o versiones oficiales de algún ministerio, la educación ha de entenderse como aquella condición del ser humano, adquirida y desarrollada en una variedad de contextos sociales, por medio de la cual la persona demuestra en su diario vivir una sensibilidad, una actitud, un pensar y una conducta "humana". Es decir, una "humanidad", que trasciende la "animalidad" y la "bestialidad". Es una condición humana fundada en la razón, en contraposición a lo irracional y lo primitivo, a lo puramente instintivo. Implica la reflexión antes que la acción. Conlleva también una sensibilidad -una forma de sentir- que se traduce en acciones nobles, fraternas, solidarias. De tal suerte que es a través de la educación que el hombre se hace hombre, es decir, el hombre adquiere su condición de ser humano y se sublima.

La educación ha de entenderse como la superación, como la conquista de la ignorancia que nace y se manifiesta en la vulgaridad y la patanería, la intolerancia y los prejuicios, los estigmas y estereotipos, la pobreza de entendimiento y la irreflexión, la miopía y la necedad, la manipulación y la opresión, la incertidumbre y los miedos, el consumismo y la anomia, los dogmas y el fanatismo, la superstición y la aberración. La educación se refiere a aquellos modales y formas de actuar que, como condición sine qua non, habilitan a los individuos a convivir en espacios sociales y naturales en paz, armonía y respeto. La educación supone posibilidades y restricciones en tanto que posibilita el desarrollo de los talentos, las potencialidades y virtudes del hombre; pero 
también constriñe los extremos, los excesos y el desenfreno de los apetitos y las bajas pasiones como el odio y la violencia.

La educación es un despertar de la conciencia del ser -de la esencia del ser humano- sobre lo que se considera bueno, justo, valioso y verdadero no solo para sí mismo sino también para los demás -otros seres además de los humanos. La educación implica templanza del carácter y pulcritud en la actuación pero también conlleva claridad, estructuración y sentido a la persona, no solo sobre una disciplina, una profesión o una dimensión de la vida, sino sobre la vida misma; es decir, de la vida y para la vida, de tal manera que esta sea plena en todos sus sentidos.

Con base a esa idea se afirma que nos falta educación. Y esa carencia se demuestra en el diario vivir en todo contexto y situación humana, por íntima, cotidiana o irrelevante que parezca.

Para el caso, demostramos falta de educación cuando nos comunicamos y expresamos. Sí, nuestro hablar y escribir dicen mucho -si no todo- de nuestra educación. Esa carencia se manifiesta cuando usamos un discurso desestructurado e impreciso, con graves problemas para relacionar y cohesionar ideas, con un vocabulario limitado, con problemas de dicción y con un acento extremadamente marcado. De igual manera, en el diario hablar se usa mucho las "groserías"; es decir, el leguaje soez, el doble sentido y a menudo el grito, tanto así que caen en la vulgaridad y la patanería. Pero además, uno de los puntos que más denota la falta de educación está en la incapacidad de escuchar, de callar y prestar atención al otro.

Lo mismo aplica cuando escribimos, solo que en este caso además de la desestructuración, incoherencia, fragmentación, dispersión de ideas y pobreza léxica hay que agregarle la incapacidad caligráfica, ortográfica y pobreza gramatical para poder comunicar un pensamiento más o menos complejo en forma clara, fluida y eficaz. Pero no solo eso, también aplica para el contenido del mensaje, cuando lo que expresamos se basa en el desconocimiento, carece de sentido, de argumento lógico y racional y lo sustentamos con el sarcasmo, la burla o la ofensa; cuando lo que expresamos sirve, con intención o sin ella, para engañar, confundir o denigrar, obteniendo con ello algún tipo de ventaja o beneficio.

Nos falta educación en la calle, cuando la caminamos y cuando conducimos. De hecho, el tráfico es un buen contexto donde manifestamos nuestra educación o nuestra carencia ya sea como conductores o como peatones. Y esa falta de educación se manifiesta cuando usamos en claxon -que en teoría nunca se debería usar-; cuando conducimos con impaciencia y abuso; cuando faltamos a la cortesía de ceder el paso; cuando gritamos improperios a otro conductor o peatón y cuando conducimos como enajenados generando peligro. Pero lo mismo pasa con el peatón cuando en vez de hacer fila hace aglomeraciones, cuando cruza la calle por cualquier lado o se lanza a la calle imprudentemente. 
En fin, nos falta educación en tanto que generamos condiciones de tránsito no solo caóticas sino también salvajes donde se impone la ley del más fuerte y no la de la razón. Nos falta educación vial en la medida que no respetamos las reglas de tránsito y urbanidad.

Nos falta educación cuando comemos. Una de las acciones más cotidianas del ser humano es comer, y también en esa acción tan cotidiana demostramos nuestra educación. Por un lado, se puede afirmar que nos falta educación en la mesa al usar o no usar los cubiertos, la forma que masticamos los alimentos, los ruidos que hacemos, la higiene con la que los cocinamos y consumimos, la limpieza de la mesa y del lugar donde se come. Pero también en el hecho de no tener conciencia de qué comemos y de cuánto comemos; de los beneficios, riesgos y consecuencias de los alimentos para la salud, el crecimiento y el desarrollo del cuerpo. Comer "bien" o comer "mal", es decir, comer sana y equilibradamente es una cuestión de educación y no una cuestión monetaria -muchos podrían argumentar que se come lo que está disponible de acuerdo con el bolsillo. La alimentación sana vinculada con la actividad física-deportes y ejercicios- previene el deterioro y enfermedades que inciden en el bienestar y la calidad de vida de las personas. Un par de ejemplos de la falta de educación, en este caso nutricional y de salud, lo constituyen el consumo de la comida chatarra y la obesidad.

Por otro lado, la basura en las calles, cerros con vocación forestal que lucen quemados y desérticos, ríos sin vida, cuerpos de agua contaminados, fauna salvaje prácticamente extinta, humo negro y espeso en el aire producido por un sistema de transporte público obsoleto, valles fértiles que en vez de productos agrícolas producen proyectos urbanísticos y asentamientos humanos precarios, y mil ejemplos más, dicen mucho también de nuestra educación. El deterioro y depredación al que sometemos nuestro medio ambiente dicen que nos falta educación ambiental. Esa carencia, como individuos y como sociedad, no nos ha permitido comprender, valorar y respetar la relación de interdependencia que mantenemos con nuestro entorno natural. Esa carencia la demostramos como falta de sensibilidad y racionalidad en el uso de los recursos naturales, con la cual ya hemos comprometido la sostenibilidad y sustentabilidad hasta de las generaciones futuras. Con esos niveles de ignorancia, no logramos comprender axiomas tan sencillos como "lo que le hacemos a la naturaleza, nos lo hacemos a nosotros mismos".

A decir verdad son muchas las actuaciones y variados los contextos en los cuales hacemos patente nuestra educación o nuestra falta de educación. Tomemos para el caso nuestra presentación personal y nuestro vestir. Esto tampoco tiene que ver con la condición económica de la persona o con la moda-como se podría argumentar- ya que una persona puede lucir sucia y desordenada o estrafalaria hasta con las prendas más caras. Esto es así porque la presentación tiene que ver con el sentido de orden, aseo, sobriedad y propiedad -y estos vienen con la educación. Veamos también las relaciones e interacciones con otras personas -familiares, amigos, colegas, desconocidos- cuando 
manifestamos un trato áspero, impertinente, insolente, descortés, irrespetuoso en vez del trato cordial y amable que toda persona se merece por el simple hecho de ser persona -lo mismo aplica para el trato de los animales. Nos falta educación cuando nos dejamos dominar por la ira y el mal carácter, cuando sucumbimos a nuestros instintos más primitivos y cuando no podemos refrenar nuestros excesos y apetitos, dejando que estos se instalen en nuestro interior en forma de vicios o que salgan en forma de violencia -en cualquiera de sus manifestaciones.

Embarazar o quedar embarazada a corta edad, traer al mundo más hijos de los que se puedan mantener-como si solo de mantenerlos se tratara-, traer hijos al mundo en condiciones de pobreza e ignorancia, sin oportunidad ni factibilidad de salir de esas condiciones, sino más bien de reproducirlas y perpetuarlas, tiene todo que ver con una gran carencia de educación. De igual manera, nos falta educación cuando pensamos que la justicia es solo divina y lo justificamos con "Es la voluntad de Dios", "Hay un Dios que todo lo mira" o "Allá arriba las va a pagar"; cuando impulsivamente compramos cosas que no necesitamos o que están fuera del alcance de nuestro presupuesto; cuando fallamos en respetar los derechos de las demás personas o en hacer valer los nuestros ante los atropellos de otros; cuando nos dejamos dominar y explotar por las arbitrariedades y abusos de los empleadores porque a lo mejor ni nos percatamos o si nos percatamos nos gana la necesidad; cuando se toma una actitud sumisa y pasiva en la vida ciudadana dejando que otros piensen y decidan.

También la falta de educación se manifiesta en situaciones más sutiles, exigentes y complejas. Para el caso, cuando nos dejamos manipular explícita o implícitamente- por personas y grupos de poder porque ni siquiera podemos discernir las intenciones ocultas; cuando al diálogo racional y honesto anteponemos la frustración, el interés, la ira, el grito y el reclamo airado o cuando la intolerancia, la imposición y el disenso se imponen al consenso. De igual forma, cuando fallamos en desentrañar fenómenos multidimensionales y multicausales o hacemos análisis superficiales, simplistas, reduccionistas 0 viscerales de realidades complejas y que solo evidencian nuestras carencias; cuando somos sumisos, pasivos, apáticos, acríticos ante una sociedad, un sistema, una realidad que se nos impone, nos abruma, nos victimiza y la cual no podemos comprender ni explicar y menos sobreponer o transformar porque nos faltan herramientas, racionalidades y marcos explicativos que solo vienen con la educación.

Por todo eso -y por muchas otras situaciones más- afirmamos que nos falta educación. Pero esta aproximación solo es posible por la forma cómo pensamos la educación, por la significación que le damos y por lo que esperamos de ella. Y eso solo es posible si la entendemos como cualificación y atributo perceptibles de una condición y construcción humana en permanente progreso a través de la cual se hace viable el proyecto de hombre- y no como acto, acción, fenómeno o proceso. Solamente si la entendemos así, podemos además explicarnos por qué muchas personas terminan el nivel secundario 0 
se gradúan de la universidad y su "educación", durante y después de este largo y costoso proceso de formación, no queda plenamente demostrada. La clave para entender la educación es sencilla: "si no te hace mejor ser humano, no es educación".

\section{Nelson Rubén Martínez Reyes}

Director y editor

San Salvador, julio de 2015 